\title{
ERICH FROMM Y LA RELACIÓN EDUCATIVA
}

\author{
Erich Fromm and the educational relationship
}

\author{
Núria OBIOLS-SUARI \\ Universitat de Barcelona. España. \\ nobiols@ub.edu \\ bttps://orcid.org/0000-0003-3103-0336
}

Fecha de recepción:08/06/2020

Fecha de aceptación: 31/08/2020

Fecha de publicación en línea: 01/11/2020

Cómo citar este artículo: Obiols-Suari, N. (2021). Erich Fromm y la relación educativa. Teoría de la Educación. Revista Interuniversitaria, 33(1), 51-69. https://doi.org/10.14201/ teri. 23415

\section{RESUMEN}

En este artículo consideraremos el vínculo entre la obra de Erich Seligmann Fromm (1900-1980) y la relación educativa. Fromm aportó una perspectiva humanista fundamental al pensamiento contemporáneo y su obra se caracterizó por hilvanar variadas influencias culturales, tales como el Antiguo Testamento, el Budismo, el Marxismo, la Sociología y, desde luego, el Psicoanálisis. El objetivo principal del presente trabajo es el de comprender mejor esta relación, considerando sus características principales. La obra de este emblemático autor invita a reflexionar sobre aspectos diversos relacionados con la educación que van desde su concepto, sus finalidades, así como diferentes características de una buena relación educativa, temática que abordaremos en este artículo. Fromm aporta una perspectiva singular y sumamente interesante que abre espacios de reflexión a partir de variados aspectos sobre la existencia humana en sus textos. En este estudio hemos analizado doce de sus obras que van desde $E l$ miedo a la libertad (1941), El arte de amar (1956) o El arte de escuchar (1995). Este análisis ha permitido seleccionar aquellos contenidos vinculados a la relación educativa. Así consideraremos lo que Fromm entiende por educación, para posteriormente concretar cuáles serían las cuestiones más esenciales en una óptima relación educativa y qué la debe caracterizar. 
Palabras clave: educación; relaciones humanas; humanismo; desarrollo afectivo; desarrollo del carácter; ser.

\section{ABSTRACT}

In this article we will consider the link between the work of Erich Seligmann Fromm (1900-1980) and the educational relationship. Fromm contributed a fundamental humanist perspective to contemporary thought and his work was characterized by weaving together various cultural influences, such as the Old Testament, Buddhism, Marxism, Sociology and, of course, Psychoanalysis. The main objective of the present work is to specify how this relationship could be better understood, considering its main characteristics. The work of this emblematic author invites to reflect on various aspects related to education ranging from its concept, its purposes, as well as to different characteristics of a good educational relationship, a subject that we will address in this article. Fromm brings a singular and extremely interesting perspective that opens spaces for reflection from various aspects of human existence in his texts. In this study we have analyzed twelve of his books ranging from Escape from Freedom (1941), The art of loving (1956) or The art of listening (1995). This analysis has allowed selecting those contents linked with the educational relationship. Then we will focus on what Fromm understands by education and after specify what would be the most essential questions in an optimal educational relationship, and what should characterize it.

Key words: education; human relations; humanism; emotional development; personality development; to be.

"Aunque tus pecados sean de color escarlata, tú serás blanco como la nieve». (Fromm, 1982, p. 196).

\section{INTRODUCCIÓN}

La obra de Erich Seligman Fromm (1900-1980) ha sido prolífica y ha ejercido una gran influencia intelectual. Consciente de ello, reivindicaba que su trabajo contribuyera a crear un "laboratorio de la vida cotidiana». (Fromm, 1985, p. 144) lejos de convertirse en un recetario mágico para vivir: «Si el lector espera en este capítulo una breve receta para aprender a vivir, será mejor que lo deje aquí». (Fromm, 1985, p. 23). Un laboratorio que permitiera vivir mejor con matices al adverbio que van desde valorar el ser antes que el tener, hasta el esfuerzo sentido y personal para amar de un modo auténtico. Es difícil resumir las influencias que lo marcaron. Desde el budismo, la ética aristotélica, Spinoza o Santo Tomás de Aquino, además de un extenso mosaico de autores como Marx, Bachofen o Freud: «ellos me permitían realizar la síntesis entre lo que consideraba vivo en la herencia del pasado y lo que amaba en el mundo contemporáneo». (Fromm, 1985, p. 162). Incluso sintonizó con B.F. Skinner, con el que a priori podría intuirse cierta distancia, a propósito de la libertad y la dignidad como bases para la existencia (Fromm, 1985). 
Desconocemos lo que Fromm pensaría sobre el panorama actual, pero resulta prácticamente imposible no cuestionárselo durante la lectura de sus obras. Un panorama en el que el ser y el tener toman un relevante protagonismo, además de estar contextualizado en un sinfín de escaparates mediáticos en los que fluyen constantemente ideas y opiniones, anónimas muchas veces. Probablemente Fromm plantearía interesantes reflexiones y las relacionaría con la necesidad de SER, auténticamente y en mayúsculas, en un presente que lo requiere.

Con el propósito de realizar el presente trabajo ${ }^{1}$ procedimos a hacer sucesivas lecturas de doce obras en las que Fromm trataba cuestiones educativas de manera directa o indirecta. Uno de los temas que nos pareció más relevante fue la relación humana y, por extensión, la educativa, fundamental en la educación y enfocado desde múltiples perspectivas que se remontan a Sócrates y la mayéutica, la cuidada relación de J.J. Rousseau con su discípulo Emilio (1762), el tacto pedagógico considerado por J.F. Herbart (1802) o la reivindicación de W. Dilthey para que sea base fundamental de la ciencia de la pedagogía (1965). La relación educativa ha protagonizado reflexiones, lo sigue haciendo y a buen seguro lo hará (Jover, 1987, 2013; Van Manen, 1998; Postic, 2000; Barba, 2002; Esteve, 2009; Romero, Bernal y Jiménez, 2009; Bárcena, 2018). De la obra de Fromm se desprenden aspectos que contribuyen a comprenderla mejor, en cualquiera de sus dimensiones, dada su aportación sumamente humana y enriquecedora.

\section{ERICH FROMM Y UNA DOCENA DE OBRAS}

Erich Seligman Fromm nació en la ciudad alemana de Frankfurt del Main el día 23 de marzo del año 1900 y murió en la ciudad suiza de Muralto, donde estaba retirado desde 1965, el día 18 de marzo de 1980. El peso de la tradición profética judía y el estudio del Talmud tuvieron una importante presencia en su vida, debido a la tradición familiar, a pesar de que abandonó el judaísmo ortodoxo junto con su primera esposa, la psicoanalista Friedda Reichmann. Fromm hizo alusión a diversas enseñanzas del Talmud, en sus escritos y conferencias, y se reconoció deudor del Antiguo Testamento por su visión de la paz universal y el amor. Además, otros

1. El inicio del presente trabajo, a modo de estudio analítico y pedagógico de una selección de obras de Fromm, se produjo a partir de la recomendación de una de sus obras a un grupo de estudiantes universitarios. En un seminario tratamos: El arte de amar (1956). Tomaron nota y, a pesar de no ser lectura obligatoria, muchos decidieron leerla y comentarla. No negaremos que tenemos la sospecha de dos factores clave. Uno es tan prosaico como que la extensión de la obra no es excesiva y, dos, lo atractivo del título. Hablar de amor en pedagogía — como hizo Miguel de Unamuno en 1902 y al que Fromm menciona en diversas ocasiones- es bastante evocador. Pero al margen de estas dos circunstancias, que pueden parecer claves de marketing para vender a Fromm —es corto y habla de amor-, lo verdaderamente interesante es que no solo lo leyeron, sino que su lectura les cautivó. Quizá Fromm podría menguar algo de passioni tristi a la que aludía M. Contini en un interesante artículo (2010). 
hechos marcaron profundamente a Fromm, como el suicidio de una amiga de la familia que hizo que reflexionara profundamente sobre la existencia humana. ${ }^{2}$

Inició sus estudios en el ámbito del Derecho en la Universidad de Ruprercht Karl de Heildeberg, pero cambió de rumbo y se dedicó al estudio de la Psicología, la Filosofía y la Sociología con Albert Weber como mentor y director de su tesis doctoral. En la misma universidad, Karl Jaspers era representante del área de Psicología y Heinrich Rickert era profesor de Filosofía.

Una de las características más notorias de Fromm fue su capacidad para hilvanar variadas influencias culturales, tales como el Antiguo Testamento, el Budismo, el Marxismo, la Sociología y, desde luego, el Psicoanálisis al que se dedicó profesionalmente en el Instituto psicoanalítico de Berlín —en el que ejerció desde 1930además de impartir docencia en la Universidad de Frankfurt, cargo que mantuvo hasta 1965. Con la llegada del partido nacionalsocialista al poder en 1934 emigró a EE. UU. donde ingresó en la Universidad de Columbia. Lo sucedido en su Alemania natal lo marcará para el resto de su vida y mencionará frecuentemente a Adolf Hitler y la psicología del nazismo. ${ }^{3}$

Sus posicionamientos intelectuales, así como sus discrepancias, han estado presentes en sus escritos. Se distanció de Herbert Marcuse y Theodor Adorno y en la obra Espíritu y sociedad (1992b) consta un texto (1937) en el que expresa sus desacuerdos con la Escuela de Frankfurt. ${ }^{4}$ Asimismo, expresó sus discrepancias y coincidencias con Freud, por ejemplo, en cuanto a la interpretación de los sueños, los cuales según Fromm no solo no son fruto de la autocensura, sino que permiten extrapolar lo mejor de nosotros «no solo somos menos razonables y menos decentes en los sueños, sino que también somos más inteligentes, más sabios y más justos cuando estamos durmiendo que cuando estamos despiertos». (Fromm, 1974, p. 34). Hablará también de Freud a propósito de la interacción social del ser humano (Fromm, 1982, pp. 34-35) y tres aspectos freudianos fundamentales: represión, resistencia y transferencia (Fromm, 1985). ${ }^{5}$

En 1943 fundó con otros colegas la filial neoyorquina de la Escuela de Psiquiatría de Washington y posteriormente, en 1950, emigró a México con su segunda esposa, Henny Gurland, donde impartió clases en la Universidad Nacional Autónoma de México y en la que fundó la Sección Psicoanalítica de la Escuela de Medicina y el

2. H. J. Shultz, uno de sus más estrechos colaboradores, hace un sugerente retrato del pensador en Un retrato dialogado (El amor a la vida, 1985).

3. Los capítulos VI en El miedo a la libertad (1982), VI en El amor a la vida (1985) y el II en La patología de la normalidad (1994) están dedicados a esta cuestión.

4. Rainer Funk, su colaborador, lo encontró en la Biblioteca pública de Nueva York con una traducción al inglés hecha por él mismo.

5. Hay que añadir también su visión sobre el amor ya que, según Fromm, Freud sobreestima la sexualidad y desprecia el eros y el amor (Peris, 2005, p. 27). Dedicó a Freud una de sus obras: Sigmund Freud's Mission: an analysis of his personality and influence (1959). 
Instituto Mexicano de Psicoanálisis (1955). Compaginó esta labor con la cátedra en la Universidad Estatal de Michigan. Fue en la década de los cincuenta, cuando Fromm da un giro a su trabajo y se centra en el ser humano en sociedad. ${ }^{6}$

En 1953 contrajo terceras nupcias con Annis Glove Freeman, que le acompañó el resto de su vida. Fromm estuvo vinculado a movimientos pacifistas y había mostrado su rechazo a la guerra del Vietnam. De hecho, su compromiso le llevó a fundar el $\mathrm{SANE}^{7} \mathrm{y}$, aunque se afilió al partido socialista, consideraba que no era suficientemente radical. Una de las iniciativas en las que Fromm participó fue en el apoyo a la candidatura de McCarthy, temática que aborda en La Revolución de la esperanza (1970).

En este trabajo seleccionamos doce obras cuyos contenidos están relacionados con la educación, como cuando la define en El arte de amar (1956) o cuando plantea sus finalidades en El miedo a la libertad (1982, p. 284).

Las obras seleccionadas son las siguientes:

TABLA 1

Obras analizadas de Erich Fromm en este trabajo y año de su primera edición

\begin{tabular}{|l|c|}
\hline OBRA & $\mathbf{1 .}^{\text {a }}$ EDICIÓN \\
\hline El miedo a la libertad & 1941 \\
\hline El lenguaje olvidado & 1951 \\
\hline El arte de amar & 1956 \\
\hline El corazón del hombre & 1964 \\
\hline La revolución de la esperanza & 1968 \\
\hline Del tener al ser & 1976 \\
\hline Sobre la desobediencia y otros ensayos & 1981 \\
\hline Amor a la vida & 1983 \\
\hline El arte de escuchar & 1991 \\
\hline La patología de la normalidad & 1991 \\
\hline El humanismo como utopía real & 1992 \\
\hline Espíritu y sociedad & 1992 \\
\hline
\end{tabular}

Fuente: Elaboración propia

6. Es interesante la conferencia impartida el día 30 de octubre de 1964 en la Universidad de UCLA en la que describe tres características del hommo actual: consumidor, tecnicista y alienado. https://www. youtube.com/watch?v=1rKRIXJaO18

7. Comité Nacional para una Política Nuclear Sana. En Los rostros de Erich Fromm (2016) se desvelan cuestiones sobre sus afiliaciones contactos con jefes de estado "para tender un puente entre los altos funcionarios del gobierno y los activistas de derechos humanos y la paz" (Friedman y Schreiber, 2016, en la presentación de la obra realizada por Gerald N. Grob). 
NÚRIA OBIOLS-SUARI

ERICH FROMM Y LA RELACIÓN EDUCATIVA

\section{QUÉ NO SIGNIFICA EDUCAR}

Cuando Fromm definió la educación en El arte de amar (1956, p. 120) lo hizo contrastando su concepto al de manipulación, concretando lo que debe ser y planteando lo que no debe ser, y el tipo de relación sobre la que no debe sustentarse:

Educación significa ayudar al niño a realizar sus potencialidades. Lo contrario de la educación es la manipulación, que se basa en la ausencia de la fe en el desarrollo de las potencialidades y en la convicción de que un niño será como corresponde solo si los adultos le inculcan lo que es deseable y suprimen lo que parece indeseable. No hay necesidad de tener fe en el robot, puesto que tampoco hay vida en él.

Sentido parejo a este fragmento de J. M. Esteve (2009, pp. 2-3):

Ni como educador ni como padre tengo derecho a determinar qué va a ser un niño, cómo va a pensar y qué va a hacer cuando sea adulto (...). Corremos a cada instante el riesgo de olvidar al sujeto y hacerlo un mero objeto de condicionamiento; y al mismo tiempo, en la vertiente opuesta, el riesgo de olvidar la construcción de la personalidad, haciendo banal la relación y olvidando dirigirla hacia una finalidad intencionalmente elegida.

Decía Fromm, en La patología de la normalidad (1994), que «la única diferencia entre el médico y el paciente es que uno de ellos tiene la llave». (p. 33) lo que, en educación, podría ser equivalente a lo que diferencia al educador del educando y con lecturas distintas en función de quien cree poseerla. Como señala Fromm y Esteve, lo de cómo manejarla sería el quid de la cuestión, además de que: «Nuestros estudiantes no son objetos para modelar ni fabricar, y por eso no podemos exigir a la educación ni garantías, ni predicciones, ni seguridades, más allá de lo razonable». (Bárcena, 2018, p. 75). Es evidente que los educandos perciben las intenciones del educador: "...los niños y la gente joven perciben instintivamente la diferencia entre aquellos que les desean el bien y quienes los consideran meramente como materia prima para algún proyecto». (Russell, 1984, p. 351). Esta idea sobre la consideración de la educación y de los roles de educador y educando está vinculada al concepto de amor que Fromm trata en El arte de amar (1956). Nos dirá que amar consiste en desear la felicidad del otro (Fromm, 1956, p. 57) dado que «el amor es una preocupación activa por la vida y el crecimiento de lo que amamos». (Fromm, 1956, p. 35). Por lo tanto, esta preocupación debe ser generosa, lo que nos aleja de la identidad inerte del educando y nos acerca a un sujeto activo cuya identidad se basa en su libertad, que es su sello de identidad (Fromm, 1994). Sería lo que queda bellamente representado en una escena de la película Cinema Paradiso (1988) cuando Alfredo (Philippe Noiret) le ordena al joven Salvatore (Marco Leonardi) que se vaya del pequeño pueblo siciliano natal y que no regrese jamás. Una imagen que nos aproxima a la idea que dar es hacer renuncias: "Para la mayoría de gente el problema del amor consiste principalmente en ser amado más que en amar». (Fromm, 1956, 
p. 9). Por otra parte, Fromm evita que su discurso pueda considerarse aval de propuestas etiquetadas de libertarias. Así como Walter Benjamin (1993) afirmaba que conseguir autenticidad de métodos educativos — que permitan equilibrio entre el desarrollo natural y la culturización del individuo- es «tarea que sin autoridad no puede llegar a resolverse jamás». (p. 50), Fromm afirma que convertir al educando en mero objeto de condicionamiento puede darse desde propuestas pedagógicas disciplinarias como desde las que, aparentemente, no hay autoridad. Por ello tacha de hipócrita la relación educativa que se basa en una autoridad anónima: «La autoridad evidente empleaba la fuerza física; la autoridad anónima emplea el manejo psíquico». Distinción que hace en el prólogo de la emblemática obra Summerbill (Neill, 1984, p. 10), cuyo proyecto educativo reivindica dado que «la autoridad no disfraza un sistema de manipulaciones». (Neill, 1984, p. 11). También Fromm tratará este concepto en Sobre la desobediencia y otros ensayos (1984, p. 10):

Un ejemplo de autoridad racional es la relación que existe entre alumno y maestro; uno de autoridad irracional es la relación entre esclavo y dueño. Ambas relaciones se basan en el hecho de que se acepta la autoridad de la persona que ejerce el mando. Sin embargo, desde el punto de vista dinámico son de naturaleza diferente. Los intereses del maestro y del alumno, en el caso ideal, se orientan en la misma dirección. El maestro se siente satisfecho si logra hacer progresar al alumno; si fracasa, ese fracaso es suyo y del alumno. El dueño del esclavo, en cambio, desea explotarlo en la mayor medida posible. Cuanto más obtiene de él, más satisfecho está. (...). Hay otra distinción paralela a ésta: la autoridad racional lo es porque la autoridad, sea la que posee un maestro o un capitán de barco que da órdenes en una emergencia, actúa en nombre de la razón que, por ser universal, podemos aceptar sin someternos. La autoridad irracional tiene que usar la fuerza o la sugestión, pues nadie se prestaría a la explotación si dependiera de su arbitrio evitarlo.

Por tanto, no debe negarse la autoridad con significado, racional y ética, la que, como diría A. S. Makarenko desde sus antípodas a Summerhill, "permite la identidad del individuo, la iniciativa y la voluntad creadora». (Makarenko, 1985, p. 37).

\section{LO QUE REQUIERE UNA BUENA RELACIÓN EDUCATIVA}

\subsection{Interés}

En La revolución de la esperanza (1970) Fromm define el interés de la siguiente manera:

'Interés' viene del latín inter-esse, o sea, 'ser entre'. Si estoy interesado, debo trascender mi yo, debo estar abierto al mundo y saltar dentro de él. El interés se funda en la disposición a la acción (...) nos permite captar intelectualmente, así como emocional y sensiblemente, el mundo exterior. (Fromm, 1970, p. 87). 
Además, sin interés es imposible conseguir relaciones auténticas que nos permitan comprender sin juzgar: «cuando se tiene la plena conciencia de ver al otro, realmente se deja de juzgar». (Fromm, 1992b, p. 133) y revierte en su conocimiento basado en la empatía: «toda persona se vuelve extraordinariamente interesante cuando entendemos su drama». (Fromm, 1992b, p. 138), lo que Fromm considera "aparte del amor pleno, es la experiencia satisfactoria, más maravillosa y más vivificante que pueda darse entre dos personas». (Fromm, 1992b, p. 134). Semejante a lo que expresa el personaje Atticus Finch, de la novela de Harper Lee Matar un ruiseñor (1960), a su hija: "...si puedes aprender un sencillo truco, Scout, te llevarás mucho mejor con todo tipo de gente. Nunca llegarás a entender realmente a una persona hasta que consideres las cosas desde su punto de vista..." (Lee, 1960, p. 45).

La empatía debe ir acompañada de un sentimiento, a menudo mal interpretado, como es la compasión:

Conocer a las personas en el sentido de conocerlas compasiva y empáticamente requiere que nos libremos de los reducidos lazos de una sociedad, raza o cultura dada y que penetremos en lo profundo de esa realidad humana en la que no somos más que humanos. (Fromm, 1970, p. 85; cursiva del original).

La compasión ha sido un controvertido término que Fromm contrapone a la filantropía o «esa forma enajenada y organizada burocráticamente de satisfacer la conciencia moral» y que obedece a:

...la necesidad de un mercado de consumo en constante expansión, la presión política de los pobres (e indirectamente el temor a una revolución), el creciente sentido de la igualdad democrática en los países industriales, etc., entre los cuales la compasión parece no contar. (Fromm, 1970, p. 86).

La pérdida de compasión y de empatía impide relaciones auténticas. Las personas heridas, maltratadas o resentidas con el mundo por sus desgracias, son las que sienten que ya han tenido bastante y, para no sufrir, se revisten de una coraza que les hace sentir el poder de lo incontable:

Habiendo perdido la empatía y la compasión, no tienen contacto con nadie ni puede entrarse en contacto con ellos. Su triunfo en la vida es no necesitar de nadie (...). La mayoría de ellos, pasan su existencia congelados afectivamente, siendo, por lo tanto, infelices hasta que sus vidas se acaban. Mas no es raro que ocurra un milagro y dé principio el descongelamiento. Simplemente puede ser que encuentren a una persona en cuya preocupación o interés ellos crean, y se abran nuevas dimensiones sentimentales. Si tienen suerte, se descongelarán totalmente y las semillas de la esperanza, que parecían haber sido destruidas, cobrarán vida una vez más. (Fromm, 1970, p. 32).

Así, la ternura, el amor, la empatía y la compasión son sentimientos que permiten establecer unas relaciones auténticas, idea que Fromm argumenta también en El arte de escuchar (1995, p. 41), basadas en un vínculo vital positivo: 
La condición más importante para el desarrollo del amor a la vida en el niño es, para él, estar con gente que ama la vida. El amor a la vida es tan contagioso como el amor a la muerte. Se comunica sin palabras ni explicaciones, y desde luego sin ningún sermoneo acerca de que hay que amar la vida.

\section{Rassman decía:}

Se educa por lo que se es más que por lo que se dice, como se enseña también lo que se es más que lo que se sabe. El poder del educador y del profesor depende menos de sus palabras que de la presencia total y silenciosa. (1976, p. 66, citado en Jover, 1987, p. 208).

Estos sentimientos que se contagian de modo natural generan el crecimiento personal lo cual disminuye la probabilidad de convertirse en un esbirro del sistema. «En el consiguiente proceso social, el hombre mismo, bien alimentado y divertido, aunque pasivo, apagado y poco sentimental, está siendo transformado en una parte de la maquinaria total». (Fromm, 1970, p. 13). Beneficioso para la necesidad mutua entre sujeto y grupo (Need to belong) (Fromm, 1985, p. 43). Esta necesidad ha sido estudiada desde múltiples perspectivas y, en especial, desde la Psicología Social en la que existen experimentos que ponen en evidencia la potencia de este deseo. ${ }^{8}$ Todos conectamos con el mundo y existe ese barco común que nos aleja de la soledad: "No hay sentido de individualidad fuera de la pertenencia de la tribu» (Fromm, 1992b, p. 56) a pesar de que "paradójicamente, la capacidad de estar solo es la condición para la capacidad de amar». (Fromm, 1956, p. 126). Una cosa es la soledad, y la capacidad para gestionarla, y la otra, la soledad que nos aleja del sentimiento social.

Fromm recalca en La revolución de la esperanza (1970) que la relación grupal presenta aspectos interesantes para aplicar en el ámbito educativo. Lo recalca citando a Paulo Freire:

...se puede aplicar incluso en la alfabetización de los campesinos pobres y de los habitantes de los barrios bajos ha sido demostrado por los métodos muy exitosos de alfabetización diseñados y aplicados en Brasil por el profesor P. Freire y ahora en Chile. (Fromm, 1970, pp. 117-118).

Existen múltiples conexiones entre el trabajo de Fromm y de Freire como el diálogo auténtico: "De este modo, el educador ya no es solo el que educa sino aquel que, en tanto educa, es educado a través del diálogo con el educando, quien, al ser educado, también educa». (Freire, 1970, p. 85). Palabras en sintonía con las siguientes de Fromm:

8. Son innumerables los experimentos que se han hecho en este sentido, pero nos gustaría destacar uno de ellos (Gino Ayal, \& Ariely, 2009) en los que se pone en evidencia que la necesidad de pertenecer a un grupo puede contradecir una conducta ética deseable (como se citó en Marco-Pallarés, 2014). 
Mediante el aumento del mutuo conocimiento de los miembros, el debate irá perdiendo el carácter áspero y de frase hecha para convertirse en un diálogo entre seres humanos y no en una disputa. Aun cuando siempre habrá fanáticos y gente más o menos enferma y necia, incapaces de participar en este tipo de discusión, se puede crear una atmósfera que por sí sola elimine la efectividad de tales individuos dentro del grupo (...). El diálogo implica siempre una mutua aclaración de quienes lo sostienen y, a menudo, la comprensión del interlocutor más que la de uno mismo. (1970, pp. 112-113; cursiva del original).

Siempre con el objetivo que el grupo tome decisiones, lo que requiere aprender: "De donde se desprende que el área de la toma de decisiones debe crecer a medida que la gente aprenda a pensar, a discutir y a hacer juicios». (Fromm, 1970, p. 113). Por decirlo con otras palabras: "Un auténtico diálogo no se propone convertir al otro a las propias ideas ni contender con él, si no establecer un intercambio». (Fromm, 1985, p. 147).

\subsection{Realismo}

Tal como hemos dicho anteriormente, Fromm enlaza a menudo la literatura con sus reflexiones, como cuando Huxley o Orwell le sirven para expresar el concepto de manipulación y control (Fromm, 1970, p. 13). También cuando considera el concepto de normalidad' ${ }^{9}$, utilizando la metáfora de la novela The country of the blind (1925) de H. G. Wells, en la que un chico vidente vive en una isla donde todos son ciegos (Fromm, 1994, p. 22). Partiendo de esta base, ser realista requiere comprender contextos. También requiere comprender la naturaleza humana, o sea, ni lobos ni corderos:

Si se cree en la bondad del hombre como la única potencialidad, se estará obligado a una falsificación optimista de los hechos o a terminar en una amarga desilusión. Si se cree en el otro extremo, terminará uno siendo un cínico y estando ciego para las muchas posibilidades para el bien de los demás y de uno mismo. Una opinión realista ve las dos posibilidades como potencialidades reales, y estudia las condiciones para el desarrollo de una u otra. (Fromm, 1975, p. 118).

No niega la existencia de la maldad:

Ante todo parto de la consideración de que el hombre es mucho más destructivo y cruel que el animal. El animal no es sádico, no es hostil a la vida, pero la historia humana es un documento de la inimaginable crueldad y la extraordinaria destructividad del hombre. (Fromm, 1985, p. 76).

9. Fromm lo detalla en la obra La patología de la normalidad y en concreto en el capítulo titulado Patología de la normalidad del hombre actual, basado en cuatro lecciones impartidas en la New School for Social Research (1953). 
Aunque se opone a un posicionamiento freudiano para el que la naturaleza humana está inclinada al mal. Lo argumenta citando a Russell y su ácida crítica a los psicoanalistas freudianos, dado que el pecado y la culpa, desde un punto de vista cristiano, se hacen livianos al compararlos con las perspectivas freudianas:

Russell expresó brillantemente sus puntos de vista sobre la supuesta maldad del hombre en Unpopular Essays (1950): Los niños, después de ser los miembros de Satán en la teología tradicional, y ángeles místicamente iluminados en la mente de los reformadores educacionales, han recaído en ser pequeños demonios, no los demonios teológicos inspirados por el Maligno, sino las abominaciones científicas freudianas inspiradas por el Inconsciente (...). ¿Es ésta, en última instancia, la verdad objetiva? ¿O es meramente una compensación imaginativa de los adultos, de que ya no se les permita zurrar a esas pequeñas plagas? Dejemos que los freudianos respondan, apoyándose unos a otros. (Fromm, 1981, p. 49).

Si utiliza las palabras de Russell para ironizar sobre la maldad y el psicoanálisis, por el contrario, utiliza las de Pau Casals para recalcar la inclinación al bien, lo que vincula evidentemente a la música:

Les diría a los hombres que en el fondo de su corazón casi todos ellos quieren más la paz que la guerra, más la vida que la muerte, más la luz que la oscuridad y luego, para aclararles lo que quiero decir, les tocaría no una composición sentimental, una de fuerte vitalidad: Bach. (Fromm, 1985, p. 176).

Fromm nos dice que el ser humano no es ni bueno ni malo «sino que hay una esencia que permanece invariable en la misma historia». (Fromm, 1992a, p. 83). Precisamente, sobre esta esencia hace el siguiente planteamiento en Espíritu y sociedad: «Creo que nacemos ya con una personalidad muy definida, que la experiencia puede torcer, deformar, modificar, pero si un manzano crece bien, dará buenas manzanas, no peras; y un naranjo dará buenas naranjas, no manzanas». (Fromm, 1992b, p. 141). Lo que tiene un evidente vínculo con el siguiente texto de Alain (Émile Auguste Chartier): "Qui observe les nature individuelles arrive bientôt à cette idée que chacune d'elles se développe suivant sa loi interne, comme un pommier, qui ne peut donner des prunes». (Chartier, 1963, p. 5). Es decir, la esencia del ser humano es determinante en su realización cuyo potencial puede ser desarrollado, lo que nos evoca a Bodgan Suchodolski cuando definía la educación "como una tarea que ha de desarrollar en el hombre todo aquello que pertenece a la realidad ideal, todo aquello que define su esencia verdadera aunque esté ahogada por la existencia empírica». (Suchodolski, 1986, p. 7).

Fromm parte de que el bien y el mal son consustanciales a la especie humana, como el conflicto en las relaciones humanas. Negarlo solo proporciona una falsificación optimista:

Los conflictos reales entre dos personas, los que no sirven para ocultar o proyectar, sino que experimentan en un nivel profundo de la realidad interior a la que pertenecen, no 
son destructivos. Contribuyen a aclarar, producen una catarsis de la que ambas personas emergen con más conocimiento y mayor fuerza. (Fromm, 1956, p. 101).

\subsection{Desobediencia}

Fromm dedicó un ensayo a la desobediencia $(1984)^{10}$ y una de las primeras cuestiones que aborda es una tipología de obediencia:

La obediencia a una persona, institución o poder (obediencia heterónoma) es sometimiento; implica la abdicación de mi autonomía y la aceptación de una voluntad o juicio ajenos en lugar del mío. La obediencia a mi propia razón o convicción (obediencia autónoma) no es un acto de sumisión sino de afirmación. (p. 10).

En el primer apartado, hemos mencionado la autoridad y la que tiene que ver con ciertas falacias humanas que Fromm tacha de sádicas. En éstas el ejercicio de la autoridad viene acompañado de una legitimación supuestamente moral, por ejemplo, cuando se dice que se hace por el bien del otro (1995). La popular expresión de Quien bien te quiere te hará llorar es bien conocida: «iCuantos desmanes no se habrán cometido bajo la coartada de este dicho popular, presuntamente pedagógico?». (Trilla, 2002, p. 198). Para Fromm, la obediencia no es rechazable para ejecutar una buena acción educativa. Incluso hace aclaraciones para que no se confunda lo que se pretende, desde determinadas perspectivas pedagógicas progresistas, con lo que debería ser:

La corrupción de las teorías de la educación progresista ha llevado a un método en que al niño no se le dice qué hacer, no se le dan órdenes ni se lo sanciona por el fracaso en ejecutarlas. El niño simplemente 'se expresa a sí mismo'. Pero desde el primer día de su vida en adelante, está lleno del impío respeto a la conformidad, del temor de ser 'diferente', del miedo de alejarse del resto del rebaño. El 'hombre-organización' educado de esta manera en la familia y en la escuela y completada su educación en la gran organización, tiene opiniones, pero no convicciones; se divierte, pero es desdichado; está incluso dispuesto a sacrificar su vida y la de sus hijos en la obediencia voluntaria a poderes impersonales y anónimos. (Fromm, 1981, p. 48).

Pasividad también considerada por Bertrand Russell como un desastre para la vida (Fromm, 1981, p. 49) y aludirá a cómo esta obediencia puede generar necrofilia poniendo de ejemplo las palabras pronunciadas por Millán Astray el 12 de octubre de $1936^{11}$ :

10. En esta obra los textos proceden de publicaciones anteriores tal como explica su segunda esposa Annis Fromm.

11. Fromm menciona a menudo estas palabras, que relaciona con la necrofilia fascista, y constan en varias obras como en El corazón del hombre (1975, pp. 27-28), en El amor a la vida (1985, pp. 176-183), en La patología de la normalidad (1994, p. 116) y en Sobre la desobediencia y otros ensayos 
El eslogan necrófilo Viva la muerte, aunque conscientemente sólo lo utilicen los fascistas, llena el corazón de muchas personas que viven en tierras de plenitud de bienes, aunque ellas mismas no se den cuenta. Parece que en este hecho reside una de las razones que explican por qué la mayoría de la gente se resigna a aceptar la guerra nuclear y la consiguiente destrucción de la civilización, y da tan pocos pasos para impedir esta catástrofe. (Fromm, 1981, p. 49).

Freire también se refirió a la relación necrófila por parte de los opresores a los oprimidos para convertirlos en objetos inanimados y poseerlos (1970). No hay duda de que el autoritarismo vinculado a una idea de destructividad, y el conformismo automático que genera, son las bases de este proceso tal como argumenta en $E l$ miedo a la libertad (1982). Aquí será donde alude a estas palabras de Isaías para argumentar que encadenarse al pasado impide la libertad "Aunque tus pecados sean de color escarlata tú serás blanco como la nieve». (Fromm, 1982, p. 196). Algo que nos recuerda a las siguientes palabras de A.S. Makarenko: "...el método fundamental de reeducación de los delincuentes se basaba en la ignorancia completa de su pasado y tanto más de los antiguos delitos». (Makarenko, 1996, p. 240). Antón Semiónovich cansado de recibir los expedientes de sus colonos sobre sus delitos, interrogatorios «y demás galimatías» (1996, p. 240) logró convencer a toda la colonia que lo mejor para su trabajo pedagógico era ignorarlos por completo «y lo hacíamos tan bien, que hasta los propios colonos no tardaban en olvidarlos». (Makarenko, 1996, p. 241). La misma idea aparece en otras obras de Fromm con otros términos: "La vida consiste en volver a nacer continuamente». (1985, p. 11). El nacimiento es un acto continuo durante toda la vida dado que lo más terrible que puede ocurrirle a un ser humano es no vivir plenamente «Lo trágico de la vida es que la mayoría de nosotros morimos antes de haber nacido plenamente». (1992b, p. 94).

Romper con el pasado permite un nacimiento continuo "para entrar en una nueva situación que solo podemos manejar con nuestras propias actividades». (1992b, p. 95). Volver a nacer «exige tener fe» (1992b, p. 95) dado que todo renacimiento genera siempre incertidumbre.

\section{LO QUE DEBE SER UNA BUENA RELACIÓN EDUCATIVA}

Hemos visto una serie de características que Fromm considera necesarias para la existencia y que hemos vinculado a la educación. Hemos observado que el interés vital es fundamental, como el realismo que nos permite desterrar la falacia de la bondad humana y la negación del conflicto. Finalmente, la necesidad de un punto

\footnotetext{
(1981, pp. 51-52) «Venceréis porque tenéis sobrada fuerza bruta. Pero no convenceréis. Para convencer hay que persuadir. Y para persuadir necesitaríais algo que os falta: razón y derecho en la lucha. Me parece inútil el pediros que penséis en España. He dicho». Tomado de Hugh Thomas, La guerra civil española. Ediciones Ruedo Ibérico, 1961, p. 295.
} 
de desobediencia para una obediencia autónoma, o educación del criterio, que nos permite romper con el pasado y volver a nacer. Pero no es suficiente para una buena relación. En El arte de amar (1956) Fromm considera los siguientes elementos para ello: cuidado, responsabilidad, respeto y conocimiento.

\subsection{Cuidado}

"El amor es la preocupación activa para la vida y por el crecimiento de aquello que amamos». Y añade: "cuando falta tal preocupación activa, no hay amor». (Fromm, 1956, p. 35). Para amar, hay que cuidar. ¿Y para educar? Fromm hace referencia a ello, con contundentes palabras, cuando habla del cuidado de una madre a su hijo dejando claro que la sobreprotección no es buena forma de cuidar y, por tanto, de amar: «sus cuidados exagerados no obedecen a un amor excesivo al niño, sino a que debe compensar su total incapacidad de amarlo». (Fromm, 1956, p. 65). Dedica en sus obras espacios a Johan Jakob Bachofen (1815-1887) por sus trabajos antropológicos sobre la silenciada presencia de la mujer en la historia (Fromm 1974 y 1985). También a las relaciones familiares y como el dominio puede contravenir cualquier gesto de amor o de cuidado dado que «La familia es la instancia psicológica de la sociedad». (Fromm, 1992b, p. 47) y, por lo tanto, en su núcleo pueden darse todo tipo de relaciones: «El niño es su objeto de dominio y, para la mayoría de las personas, incluso el único». (Fromm, 1992b, p. 41), "Un gesto soberbio, un centelleo sádico de los ojos y un tono de voz amenazador son mucho más comprensibles para el niño pequeño, incluso más comprensibles que para el adulto». (Fromm, 1992b, p. 47).

\subsection{Responsabilidad}

Fromm dirá que la responsabilidad es otra «experiencia humana típica». (Fromm, 1970 , p. 88). Un término que ha perdido su significado original y se emplea como un sinónimo del deber. Craso error si tenemos en cuenta que responsabilidad es un término vinculado a la libertad: un ser humano es libre cuando asume plenamente sus responsabilidades. En otras ocasiones relaciona la responsabilidad a prácticas profesionales. Por ejemplo, el fraude de recetas vitales fáciles, así como los mantras a medida "que permite vendérselo al novato por una bonita suma». (Fromm, 1991, p. 30) y que pertenece a lo que él le llama el «bufet libre espiritual». (Fromm, 1991, p. 29) que pretende la "salvación del hombre, de su bienestar, desarrollo y felicidad». (Fromm, 1991, p. 27). Un engaño que impide que la biofilia se edifique en «el terreno firme del realismo». (Fromm, 1991, p. 35).

\subsection{Respeto}

Una de las bases del respeto entre personas es el reconocimiento de la particularidad del otro. El respeto es "la capacidad de ver una persona tal como es, 
tener conciencia de su individualidad única». (Fromm, 1956, p. 37). Para explicar la promoción del respeto hacia los demás, cita a Marx en El Amor a la vida (1985) y hace referencia al experimento de Elton Mayo en la Western Electric Company — cuya colaboración tuvo lugar entre 1927 y 1932 - en el cual se puso en evidencia que las personas se sienten realizadas cuando se sienten partícipes. Lo que en La patología de la normalidad (1994) plantea cómo de absurda puede ser nuestra época que solo nos permite vivir el trabajo como parte de un proceso productivo. «El hombre es sano si puede cumplir las funciones que está le atribuye, si puede obrar de acuerdo con las necesidades de una sociedad determinada». (Fromm, 1994, p. 99). De hecho, la futilidad del trabajo solo genera pereza y sensación de estafa (Fromm, 1992a).

El respeto es básico para la educación:

Libertad no implica libertinaje. Este principio tan importante, que Neill subraya, significa que el respeto entre los individuos debe ser recíproco. El maestro no emplea la fuerza contra el niño, y el niño no tiene derecho a usarla contra el maestro. El niño no tiene por qué meterse en las cosas de un adulto por ser niño, ni ejercer presión en ninguna de las muchas maneras en que puede hacerlo un niño. (Neill, 1984, p. 12).

O, como decía Herbart: «No one can be allowed to treat a child as a plaything. On the other hand, no one must allow himself to be ruled by a child (...)». (Herbart, 1901-4). Jover (2013) dice en su definición de relación educativa:

No respeta al sujeto en formación quien, sirviéndose del vínculo de dependencia que los une, pretender hacer de él otro yo, en lugar de ayudarle a alcanzar su propio modo de situarse en el mundo. Pero tampoco lo respeta quien, escudándose en la cómoda opinión de que toda influencia es un atentado contra la libertad del otro, lo deja en un irrespetuoso estado de permanente minoría de edad, sin impulsarlo y ayudarlo en la aventura de fraguar un sí mismo.

También se respeta reconociendo su intimidad:

La única manera en que los padres y los profesores pueden guiar adecuadamente a sus hijos y alumnos hacia la edad adulta es precisamente no conociendo lo que está pasando en la mente del niño y no sabiendo exactamente lo que el niño hace. De otra manera, no puede emerger la individualidad del niño. (Van Manen y Levering, 1996, p. 132).

\subsection{Conocimiento}

Un conocimiento que nos hace crecer plenamente y requiere una adquisición paulatina. Fromm nos habla del mito judío del Talmud en el que se explica que al nacer el niño lo sabe todo "pero sería tan doloroso nacer con este conocimiento que un ángel, por comprensión, toca al niño y le hace olvidarlo». (Fromm, 1992b, p. 105). El conocimiento se encuentra vinculado al acto de amar: 
...el conocimiento psicológico, es una condición necesaria para el pleno conocimiento en el acto de amar. Tengo que conocer a la otra persona y a mí mismo objetivamente, para poder ver su realidad, o más bien, para dejar de lado las ilusiones, mi imagen irracionalmente deformada de ella. (Fromm, 1956, p. 39).

Este a mí mismo objetivamente, parejo al lema délfico Conócete a ti mismo - que por supuesto no solo Fromm empleará para que se comprenda su importancia - implica una inevitable metamorfosis, la cual recuerda citando a Heráclito (1985, p. 28): "Es imposible entrar dos veces en el mismo río", por tanto no debe comprenderse el conocimiento como un dogma (Fromm, 1994) y debe sustentarse al esfuerzo para conquistarlo, lo que para Fromm no deja de ser un modo de respetar al educando pedirle esfuerzo y no engañarlo con que la vida es posible sin este ni dolor: "Del profesor que insiste en el trabajo se dice que es autoritario o chapado a la antigua». (Fromm, 1991, p. 41). A ello ayuda nutrirse de modelos que contribuyan a transmitir ciertas actitudes humanas: «Este punto se puede ilustrar con un relato jasídico. Una vez le preguntaron a un discípulo de un maestro jasídico: «Por qué vas a escuchar al maestro? ¿Es para oír sus palabras de sabiduría?» Y la respuesta no se hizo esperar:

¡Oh, no; voy a ver cómo se ata sus sandalias! (...) Así, lo que importa en una persona no es el conjunto de ideas u opiniones que acepta, sea porque ha estado expuesto a ellas desde la infancia o porque constituyen patrones convencionales de pensamiento, sino el carácter, la actitud, la raíz visceral de sus ideas y convicciones. (Fromm, 1970, p. 134).

Es un conocimiento desde modelos determinados «Si la generación siguiente deja de ver esos rasgos, se derrumbará una cultura de cinco mil años, aunque su conocimiento se transmita y se siga desarrollando». (Fromm, 1956, p. 114). Fernando Bárcena, rememorando la descripción que hacía Peter Handke de sus profesores universitarios en su Ensayo sobre el cansancio (1989), nos decía lo siguiente: «En su evocación, Handke no se queja de la ausencia ni de didácticas ni de metodologías pedagógicas. Se queja de la falta de pasión de sus profesores. De su falta de amor por lo que hacían y enseñaban». (Bárcena, 2018, p. 85), lo que afecta en cómo vive el estudiante sus clases y que expresaba Walter Benjamin en 1915 sobre su apatía: "Desde el punto de vista del sentimiento estético, he aquí lo más chocante y mortificante de la universidad: la atención mecánica con que el auditorio sigue las lecciones». (Benjamin, 1993, p. 127). O cuando las sandalias son lo de menos.

\section{CONCLUSIONES}

En este artículo hemos tratado de vincular algunas cuestiones planteadas por Fromm en doce de sus obras a la relación educativa. Hemos iniciado el texto con el significado de buena educación, alejada de manipulación y de considerar al educando un mero objeto inerte. Ello requiere la generosidad del educador que desea su libertad y la toma de sus decisiones. Considerando también el concepto 
de autoridad deseable, o racional, y la rechazable, o irracional. De esta segunda categoría Fromm destaca la autoridad anónima, propia de las pedagogías disfrazadas de libertarias, y la evidente, presente en acciones disciplinarias.

Por otra parte, Fromm destaca elementos necesarios en las relaciones humanas. El primero hace referencia al interés hacia el mundo y, por ende, hacia el ser humano. Un interés basado en la compasión que permite acercarnos sin juzgar para hallar lo más auténtico del otro, lo que requiere empatía. Un interés que se traduce en el amor a la vida y que se aleja de sermoneos, para contagiarse de un modo natural y que se transforma en un diálogo auténtico. El segundo es la dosis necesaria de realismo para comprender que las circunstancias nos determinan y que el conflicto es tan inevitable como la dualidad humana. Considerar únicamente la maldad nos hace cínicos, así como la bondad en exclusiva es garantía de una amarga desilusión. La esencia humana nos determina, como recalca la metáfora de las manzanas o naranjas y que aparejan a Alain con Fromm. El tercer elemento sería la desobediencia entendida como una obediencia autónoma, lo contrario a la heterónoma que debilita la conciencia humanística. No es rechazable la obediencia y sí lo es cuando supone la condena al conformismo, lo que puede generar necrofilia y se ampara en la destructividad y el conformismo automatizado. Ello impide sanear la vida para volver a empezar, frecuente cuando no se pueden romper los vínculos con el pasado. Cómo hemos comentado, renacer exige tener fe, algo imprescindible en la acción educativa. Por otra parte, hemos considerado características que hacen referencia al cuidado, en el sentido más próximo posible a la libertad. Ser libre implica asumir responsabilidades, además de que «de lo que se trata es de que el hombre trascienda su narcisismo, su egoísmo, su aislamiento interior (...). Como diría Eckhart, se vacíe totalmente para adquirir total plenitud, para recibirlo todo, para dar totalmente». (Fromm, 1958, p. 168) Además Fromm también recalca la responsabilidad profesional, evitando recetarios fáciles. La relación educativa debería ser respetuosa con la intimidad. Y en última instancia considerando que el conocimiento requiere esfuerzo e interés: Lo que Fromm plantea como finalidad: la formación del carácter, un tema fundamental en su obra y que vincula explícitamente a la estimulación del pensamiento crítico.

No sería tan difícil para el individuo comprenderse sin engaños si no estuviese expuesto constantemente a que le laven el cerebro y lo priven de la capacidad del pensamiento crítico (...) será incapaz de conocerse a sí mismo tal como es, porque sólo conocerá al que quieren que él sea. (Fromm, 1991, p. 101).

Rainer Funk fue uno de sus más estrechos colaboradores del que nos gustaría destacar este interesante apunte que hace sobre Fromm en el epílogo de Del tener al ser (1991). Una manera de poner las ideas en claro, si no lo estaban suficientemente en su obra: «Fromm no propugna el ascetismo (...) se trata sólo de la importancia del tener; tanto como del no tener, para el propio sentido de la vida y para el sentimiento de la propia identidad,. (Rainer Funk, en: Fromm, 1991, p. 158). Algo bastante necesario en los tiempos que corren. 


\section{REFERENCIAS BIBLIOGRÁFICAS}

Barba Martín, L. (2002). Pedagogía y relación educativa. Universidad Nacional Autónoma de México.

Bárcena, F. (2018). Maestros y discípulos. Anatomía de una relación. Teoría de la educación. Revista Interuniversitaria, 30 (2), 73-108. https://doi.org/10.14201/teoredu30273108

Benjamin, W. (1993). La metafísica de la juventud. Paidós I.C.E/U.A.B.

Chartier, E. A. (Alain). (1924). Esquisses d'Alain. 1. Pédagogie Enfantine (1924-1925). PUF. http://classiques.uqac.ca/classiques/Alain/esquisses_Alain/1_pedagogie_enfantine/ pedagogie_enfantine.html

Contini, M. (2010). Etica della professionalità educante, tra "Passioni triste», empowerment e resistenza. Teoría de la Educación, Revista Interuniversitaria, 22(1), 19-41. https:// revistas.usal.es/index.php/1130-3743/article/viewFile/7130/8297

Dilthey, W. (1965). Fundamentos de un sistema de Pedagogía. Losada.

Esteve, J. M. (2009). La urdimbre de la relación educativa. XXVIII Seminario Interuniversitario de Teoría de la Educación. http://redsite.es/docu/28site/Jose\%20Manuel\%20Esteve\%20 Zarazaga.pdf

Freire, P. (1970). Pedagogía del oprimido. Siglo XXI.

Friedman, L.J. y Schreiber, A. K. (2016). Los rostros de Erich Fromm: una biografía. FCE.

Fromm, E. (1956). El arte de amar: una investigación sobre la naturaleza del amor. Paidós.

Fromm, E. (1970). La revolución de la esperanza: hacía una tecnología humanizada. FCE.

Fromm, E. (1974). El lenguaje olvidado. Hachette.

Fromm, E. (1975). El corazón del hombre. FCE.

Fromm; E. (1982). El miedo a la libertad. Paidós.

Fromm, E. (1984). Sobre la desobediencia y otros ensayos. Paidós.

Fromm, E. (1985). El amor a la vida. Paidós.

Fromm, E. (1991). Del tener al ser. Paidós.

Fromm, E. (1992a). El humanismo como utopía real. La fe en el hombre. Paidós.

Fromm, E. (1992b). Espíritu y sociedad. Paidós.

Fromm, E. (1994). La patología de la normalidad. Paidós.

Fromm, E. (1995). L'arte di scoltare. Mondadori.

Funk, R. (s.f.). Erich Fromm Institute. Tübingen, Alemania. Erich Fromm online. https:// fromm-online.org/en/

Gino F., Ayal, S. \& Ariely, D. (2009). Contagion and Differentiation in Unethical Behavior. The effect of the One Bad Apple on the barrel. Psychological Science, 20(3), 393-398. https://doi.org/10.1111/j.1467-9280.2009.02306.x

Herbart, J. F. (s. f.). Informes de un preceptor. Ediciones de la Lectura.

Herbart, J. F. (1901-1904). Outlines of educational doctrine. The Macmillan Company. https:// www.gutenberg.org/files/44905/44905-h/44905-h.htm\#Part-II_Section-IV_Chapter-I

Jover, G. (1987). El sentido de la intencionalidad en la relación educativa. Revista Española de Pedagogía, 45(176), 207-225. https://revistadepedagogia.org/xlv/no-176/el-sentidode-la-intencionalidad-en-la-relacion-educativa/101400044154/ 
Jover, G. (2013). Relación educativa. En A. N. Salmerón, B. F. Trujillo, A. Rodríguez y M. De la Torre (Eds.), Diccionario Iberoamericano de Filosofía de la educación. https://www. fondodeculturaeconomica.com/API/DIFE/definicion. aspx?l=R\&id=12\&w=jover

Lee, H. (1960). Matar un ruiseñor. HarperCollins Ibérica.

Makarenko, A. S. (1985). Conferencias de educación infantil. Ediciones Quinto Sol.

Makarenko, A. S. (1996). Poema pedagógico. Ediciones Akal.

Marco-Pallarés, J. (2014). El nen que mira la lluna. Un recorregut per la psicologia i la neurociencia cognitiva. Ensiola editorial.

Moll, J. (2003). Definición de relación educativa. En J. Houssaye (Ed.), Cuestiones pedagógicas. Enciclopedia histórica (pp. 371-381). Siglo XXI.

Neill, A.S. (1960-1984). Summerhill. FCE.

Peris, M. (2005). Erich Fromm: Sociedad, vida y teoría. Su relación con la Escuela de Frankfurt. (Trabajo de Máster) Universidad Complutense de Madrid. https://webs.ucm.es/info/ eurotheo/e_books/tesinas/manuelperis.pdf

Postic, M. (2000). La relación educativa. Narcea.

Rassman, J. (1976). Le professeur et les éleves. Revue Thomiste, 76(1), 59-76.

Romero, C., Bernal, A. y Jiménez, J. R. (2009). Tejiendo vínculos: la textura de la relación educativa. XXVIII Seminario Interuniversitario de Teoría de la Educación. http://www. ugr.es/ fjjrios/pdf/m-ponencia3.relacionEducativa.pdf

Russell, B. (1916-1984). Escritos básicos II. Planeta-Agostini.

Sucholdolski, B. (1986). Pedagogia de l'essència i pedagogia de l'existència. Eumo.

Trilla, J. (1998). Aprender, lo que se dice aprender... Una teoría alfabética de la educación. Octaedro.

Van Manen, M. (1998). El tacto en la enseñanza: el significado de la sensibilidad pedagógica. Paidós.

Van Manen, M. y Levering, B. (1996). Los secretos de la infancia, privacidad e identidad. Paidós. 